\title{
Dynamic compared to rigid fixation in lumbar spine: a systematic review
}

Ricardo Vieira Botelho ${ }^{1}$, Rafael Bastianello Junior ${ }^{2}$, Luciana DiniGianini de Albuquerque ${ }^{2}$, Wanderley Marques Bernardo ${ }^{3}$

${ }^{1}$ Post Graduation in Health Sciences at IAMSPE-São Paulo, SP, Brazil

${ }^{2}$ Medicine School of the City University of São Paulo (UNICID), São Paulo, SP, Brazil

3University of São Paulo (USP) and Lusíadas University, São Paulo, SP, Brazi

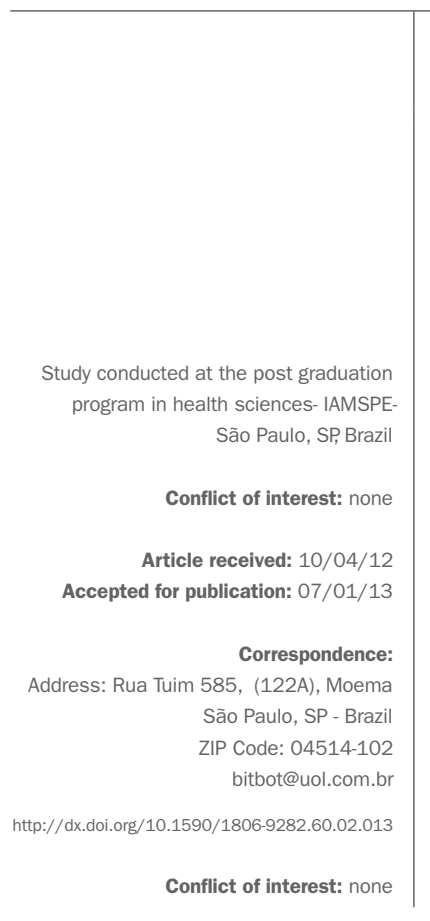

\section{SUMmARY}

Objective: The objective of this review is to reveal the quality of published data and the effect size of DPFs compared to rigid fixation in lumbar spine. Summary of background data: since 2002, several dynamic pedicle fixation (DPF) systems have been developed with the aim to stabilize the spine without the undesirable effects of rigid lumbar spine fixation. Nearly ten years later, there are several studies on these dynamic systems.

Methods: A systematic review was done in MEDLINE/PubMED, Embase, Cochrane Central Register of Randomized Trials and Google Scholar to assess the quality of published literature and the available studied outcomes in randomized controlled trials of DPF.

Results: Only three papers described randomized trials studying DPF. One of them focused on protection of adjacent level disease provided by DPF.

Conclusion: It was not possible to reveal any evidence for benefits using DPF compared to rigid fixation in surgery for lumbar spine.

Key words: lumbar vertebrae, intervertebral disc degeneration, surgical fixation devices, internal fixators, bone screws, spinal fusion.

\section{INTRODUCTION}

Fusion using spine fixation is a surgical intervention used for the treatment of degenerating lumbar spine. ${ }^{1,2}$ For patients with vertebral instability and those with painful conditions secondary to disc degeneration, the elimination of the vertebral joint movement could produce clinical improvement from the stabilization of the spine. ${ }^{3}$ Although there can be favorable clinical outcomes for certain conditions, complications of fusion with rigid fixation have appeared, such as intervertebral disc degeneration adjacent to fusion. ${ }^{4,5}$

To reduce or eliminate the undesirable effects of rigid fixation, dynamic systems have been developed based on flexible screws and rods (DPF). These implements could protect the spine from mechanical overload imposed by the rigid fixation of the spine while retaining spine movement and preventing adjacent disc degenerative disease. ${ }^{6,7,8}$

A decade after the first description of the dynamic fixation devices, some authors claim that indications for these devices are not yet defined, although there are potential diseases that could benefit from their use. ${ }^{9,10}$ The objective of this study is to evaluate the clinical outco- mes of these procedures compared with rigid pedicle fixation systems.

\section{Methods}

A systematic literature review was performed for publications between January 2002 (the first DPF publication date $^{6}$ ) and August 18, 2011, in the following electronic primary literature databases: MEDLINE/PubMed, the Cochrane Central Register of Controlled Trials (CENTRAL) and EMBASE. Google Scholar and electronic database search engines were used, and publications in all languages were included.

The research protocol was based on the method of questions structured by types of participants (study population), comparing the two types of intervention (rigid, and semirigid or dynamic fixation) and selecting the type of study as a prospective randomized trial (appendix 1). ${ }^{11}$

\section{Study population}

Adult patients with symptoms of lumbar spine degenerative disease who were not previously submitted to sur- 
gery. Patients with infection, trauma, surgical treatment of osteoporosis, and comorbidities that interfere with walking were excluded.

\section{Intervention}

Patients who underwent DPF.

\section{Control}

Patients who underwent rigid fixation.

\section{Outcome}

To reveal the effect on all outcomes studied, all reported outcomes were compared.

Type of selected studies

Randomized trials.

\section{Study selection}

Searches were performed by three independent reviewers. The papers were initially assessed by title, and those selected were subsequently re-analyzed by abstract. The references of selected articles were studied to find other relevant citations. Disagreements were solved among the authors through discussion. The search strategy is detailed in appendix 1.

\section{Quality of papers selected for study}

Because of the importance and prevalence of degenerative disease of the lumbar spine, only randomized controlled trials (RCTs) were included due to the more compelling evidence they provide. Assessments of methodological quality were made according to Cochrane collaboration's tool for assessing risk of bias (table 1$).{ }^{12}$

\section{RESULTS}

The electronic search revealed a total of 321 articles. Of these, 302 studies were categorized as human clinical trials and published as journal articles or conference papers. Selection by title identified 27 articles that were subsequently reviewed by abstract, resulting in four articles. However, one of the papers (Putzier et al.) was not randomized and was excluded. ${ }^{13}$

\section{Description of included studies and assessment of methodolo- gical quality \\ Evaluation of final three papers:}

- Korovesis et al. ${ }^{14}$ The study population was composed of patients with lumbar canal stenosis. Patients were treated with rigid fixation and dynamic system (Twinflex). All patients were fused with autograft. Thirty patients were examined 3 months after surgery. There was no description of the randomization method and no blinded allocation attempt. This study did not detail clinical outcomes. Lumbar lordosis, sacral inclination, intervertebral angle, and intervertebral disc index were evaluated. Comparisons were not made between the randomized groups, only within groups regarding pre- and postoperative outcomes.

- Korovesis et al. ${ }^{15}$ As in the first work by the same author, the study population was composed of patients with lumbar canal stenosis. Patients were treated with dynamic, semirigid and rigid fixation. All patients underwent bone fusion with bone grafts from the iliac crest. Forty-five patients were randomized, but the randomization method was not described and there was no attempt to conceal allocation. Radiological evaluation was done by independent evaluators. Clinical outcomes assessed were the visual analogic scale VAS for back pain and lower extremity. The quality of life questionnaire F-36 was also used. Degeneration and complication rate adjacent to the surgery site and failures of the systems were evaluated. Apparently there were no differences in VAS between the groups, and authors did not provide statistical analyses between groups. There were no differences in the final clinical or radiological evaluations. The complication rate evaluation revealed that it was too low to allow for comparisons. There was no degeneration in any of the adjacent groups. The analysis of provided radiological findings suggest that results were compared within each group, pre- and postoperatively, but not among the three randomized groups.

- Putzier et al. ${ }^{16}$ The authors studied patients with low back pain, presence of Modic signs, lumbar spine facet arthritis and spondylolisthesis. Sixty patients were studied comparing dynamic and rigid fixation. Randomization was performed by a specific software program, and there was no attempt to conceal allocation. The sample size of patients to be studied had been calculated previously and there was an adequate description of follow-up loss of patients. The final follow-up period was 6 years. Clinical outcomes were the rate of satisfaction with treatment, the ODI, and the VAS. Radiological evaluation consisted of changes in vertebral plateau sign (Modic sign) and the Fujiwara facet arthritis degeneration index, intervertebral disc height and presence of dynamic instability in plain radiographs. There were no differences between groups in any of these outcomes.

\section{Risk of bias in included studies (Table 1)}

There are few randomized trials studying the dynamic versus rigid fixation. Each of the identified studies had 
some kind of methodological weakness. Due to the nature of surgical intervention, blinding of treatment execution and evaluation was not possible (double-blind). Only one of the three papers described the randomization method. In one study, there was no assessment of clinical outcome (Korovesis et al.) and in the others, only the VAS was used. Outcomes were determined by the staff that performed the procedures. Korovesis et al., followed the outcomes for just three months, and Korovesis et al., followed the outcomes for two years. The final pooled analysis consisted of only 135 patients, and the low methodological quality of the papers introduces considerable potential for bias.

\section{Discussion}

Lumbar spine Degenerative Disc Disease (DDD) causes social, economic and financial burden to patients affected. It is estimated that annual expenditures for treatment cost are higher than those for all types of cancer combined. Current studies suggest that DDD has a strong genetic component and progressive evolution. ${ }^{17}$ Due to complications of spinal fusion, semi-rigid and dynamic systems have been developed to protect the spine against adjacent disk degeneration disease and to eventually ameliorate the mechanical effects superimposed on normal spine by rigid spine fusion. ${ }^{9}$ It has been suggested that these systems can return the degenerated intervertebral disc to a normal condition and eventually slow or reverse the degenerative process. ${ }^{7}$ Here, randomized studies that compared the two types of systems were evaluated. Due to the economic and financial importance of these systems, only randomized trials were analyzed. Studies comparing effect sizes based on nonrandomized trials illustrate that lower quality manuscripts tend to increase effect size. Even among RCTs, distortion of the actual effects can occur when randomization and allocation concealment are not performed properly, or when there is a high degree of follow-up loss. ${ }^{18,19,20}$

TABLE 1. The Cochrane Collaboration's tool for assessing risk of bias

\begin{tabular}{|c|c|c|c|}
\hline Author/Year & Korovesis et al. 2002 & Korovesis et al. 2004 & Putzier et al. 2010 \\
\hline \multicolumn{4}{|l|}{ Domain } \\
\hline \multicolumn{4}{|l|}{ Selection bias } \\
\hline $\begin{array}{l}\text { Random sequence } \\
\text { generation. }\end{array}$ & No & No & $\begin{array}{l}\text { Randlist Software } \\
\text { (Datalnf GmbH, Tübingen, Germany). }\end{array}$ \\
\hline Allocation concealment. & No & No & No \\
\hline \multicolumn{4}{|l|}{ Performance bias } \\
\hline $\begin{array}{l}\text { Blinding of participants } \\
\text { and personnel } \\
\text { Assessments should be } \\
\text { made for each main } \\
\text { outcome (or class of } \\
\text { outcomes). }\end{array}$ & No & $\begin{array}{l}\text { Radiological criteria were } \\
\text { analyzed by independent } \\
\text { evaluators. }\end{array}$ & $\begin{array}{l}\text { The blinded radiographs were evaluated } \\
\text { independently by both a radiologist specializing in } \\
\text { spinal imaging and an orthopedic surgeon. A second } \\
\text { independent orthopedic surgeon was consulted to } \\
\text { adjudicate conflicting fusion findings. }\end{array}$ \\
\hline \multicolumn{4}{|l|}{ Detection bias } \\
\hline $\begin{array}{l}\text { Blinding of outcome } \\
\text { assessment } \\
\text { Assessments should be } \\
\text { made for each main } \\
\text { outcome (or class of } \\
\text { outcomes). }\end{array}$ & No & $\begin{array}{l}\text { Radiological criteria were } \\
\text { analyzed by independent } \\
\text { evaluators. }\end{array}$ & $\begin{array}{l}\text { The blinded radiographs were evaluated } \\
\text { independently by both a radiologist specializing in } \\
\text { spinal imaging and an orthopedic surgeon. A second } \\
\text { independent orthopedic surgeon was consulted to } \\
\text { adjudicate conflicting fusion findings. }\end{array}$ \\
\hline \multicolumn{4}{|l|}{ Attrition bias } \\
\hline $\begin{array}{l}\text { Incomplete outcome } \\
\text { data Assessments should } \\
\text { be made for each main } \\
\text { outcome (or class of } \\
\text { outcomes). }\end{array}$ & $\begin{array}{l}\text { No (only three } \\
\text { months of FU). }\end{array}$ & There were no follow-up losses. & $\begin{array}{l}\text { The mean long-term follow-up was } 76.4 \text { months } \\
\text { ( } 60-91 \text { months). Five patients ( } 5 / 30) \text { from the SLF } \\
\text { group and eight patients ( } 8 / 30 \text { ) from the DFT group } \\
\text { failed to attend every follow-up and were therefore } \\
\text { excluded. }\end{array}$ \\
\hline \multicolumn{4}{|l|}{ Reporting bias } \\
\hline Selective reporting. & $\begin{array}{l}\text { Only radiographic } \\
\text { findings were studied. }\end{array}$ & No & \\
\hline
\end{tabular}


The first description of dynamic screw fixation was published in 2002. Although there is extensive literature related to biomechanical and case series studies, 3,21,22,23,24,25 only three randomized trials compared dynamic pedicle fixation with rigid fixation. ${ }^{14,15,16}$ It is remarkable that the three RCTs used bone fusion in both rigid and dynamic fixation. Two of the three studies failed to make direct comparisons between rigid and dynamic techniques. Rather, they compared the outcomes within each group, between pre- and postoperative status. ${ }^{14,15}$

Among all lumbar degenerative diseases, lumbar spinal stenoses were the focus in two studies, ${ }^{14,15}$ and the third study assessed a group of patients with heterogeneous degenerative disc disease, characterized by Modic type changes in the vertebral plateau, facet arthritis and spondylolisthesis. ${ }^{16}$ In this study, which had the longest follow-up time and best design, the incidence of degeneration adjacent to the fusion site was directly and objectively appraised. Six years after surgery, there was no evidence of protection against adjacent degeneration with dynamic systems.

\section{Conclusion}

\section{Implications for practice}

Although dynamic systems have been designed to protect the spine from undesirable rigid fixation effects, ten years of clinical use have failed to show superiority of these systems in clinical or radiographic outcomes. There were no differences in the rate of degeneration in adjacent dynamical systems compared with rigid systems.

\section{Implications for research}

There are few randomized trials comparing both systems, and the methodological quality still needs to be improved. Specific areas to address include the categories of independent randomization, blinding and follow-up duration.

Disclosure of funding received for this work: Rafael Bastianello Junior, Luciana DiniGianini de Albuquerque received grants from the Institutional program of scientific initiation scholarships (PIBIC/CNPq).

\section{Resumo}

Fixação pedicular dinâmica comparada com a fixação rígida na coluna lombar: uma revisão sistemática

Objetivo: Desde 2002, vários sistemas de fixação dinâmica pedicular (FDP) foram desenvolvidos com o objetivo de estabilizar a coluna vertebral, sem os efeitos indesejáveis da fixação da coluna lombar rígida. Cerca de 10 anos mais tarde, existe uma série de estudos sobre os sistemas dinâmicos. Revelar a qualidade dos dados publicados e o tamanho do efeito da FDP em comparação com a fixação rígida na coluna lombar.

Métodos: Uma revisão sistemática foi feita utilizando MEDLINE/ PubMed, Embase, a CENTRAL Cochrane de ensaios randomizados e Google Scholar para avaliar a qualidade da literatura publicada e os desfechos estudados disponíveis em ensaios clínicos randomizados.

Resultados: Apenas três estudos randomizados foram encontrados. Um deles estudou a proteção de degeneração no nível adjacente à fixação rígida proporcionada pela FDP. Conclusão: Não foi possível revelar qualquer evidência de benefícios da FPD, em comparação com a fixação rígida em cirurgia para a coluna lombar.

Unitermos: doenças da coluna vertebral, dor lombar, instrumentação, fusão vertebral, degeneração do disco intervertebral.

\section{References}

1. Gelalis ID, Arnaoutoglou C, Christoforou G, Lykissas MG, Batsilas I, Xenakis T. Prospective analysis of surgical outcomes in Patients Undergoing decompressive laminectomy and posterior instrumentation for degenerative lumbar spinal stenosis. Acta Orthop Traumatol Turc. 2010;44:235-40.

2. Bono CM, Lee CK. Critical analysis of trends in fusion for degenerative disc disease over the past 20 years: Influence of technique on fusion rate and clinical outcome. Spine. 2004;29:455-63.

3. Nockels RP. Dynamic stabilization in the surgical management of painful lumbar spinal disorders. Spine. 2005;30(16 Suppl):S68-S72

4. Anandjiwala J, Seo JY, Ha KY, Oh IS, Shin DC. Adjacent segment degeneration after lumbar spinal posterolateral fusion with instrumentation in elderly patients. Arch Orthop Trauma Surg. 2002;122:39-43.

5. Cheh G, Bridwell KH, Lenke LG, Buchowski JM, Daubs MD, Kim Y, Baldus C. Adjacent segment disease following lumbar / thoracolumbar fusion with pedicle screw instrumentation: a minimum 5-year follow-up. Spine. 2007;32:2253-7.

6. Rajaratnam SS, Mueller M, Shepperd JAN, Mulholland RC. Dynesis stabilization of the lumbo-sacral presentation spine. Poster Britspine. In: The Second Combined Meeting of the BSS BASS BCSS SBPR, Birmingham; 2002 .

7. Schmoelz W, Huber JF, Nydegger T, Dipl-Ing, Claes L, Wilke HJ. Dynamic stabilization of the lumbar spine and its effects on adjacent segments: an in vitro experiment. J Spinal Disord Tech. 2003;16:418-23.

8. Khoueir P, Kim KA, Wang MY.Classification of posterior dynamic stabilization devices. Neurosurg Focus. 2007;22(1):E3.

9. Mulholland RC, Sengupta DK. Rationale, principles and experimental evaluation of the concept of soft stabilization. Eur Spine J. 2002;11(Suppl 2):S198-205.

10. Schnake KJ, Schaeren S, Jeanneret B. Dynamic stabilization in addition to decompression for lumbar spinal stenosis with degenerative spondylolisthesis. Spine. 2006;31:442-9.

11. Van Tulder M, Furlan A, Bombardier C, Bouter L. Updated method guidelines for systematic reviews in the Cochrane Collaboration Back Review Group Spine. 2003;28:1290-9.

12. Higgins JPT, Green S Altman DG. Assessing risk of bias in studies included. Cochrane Handbook for Systematic Reviews of Interventions: Chapter 8. Cochrane Book Series.

13. Putzier M, Schneider SV, Funk JF, Tohtz SW, Perka C. The surgical treatment of the lumbar disc prolapse: nucleotomy with additional transpedicular dynamic stabilization versus nucleotomy alone. Spine. 2005;30(5):E109-14 
14. Korovessis P Papazisis $Z$ Lambiris E. The role of rigid vs..dynamic instrumentation for stabilization of the degenerative lumbosacral spine. Stud Health Technol Inform. 2002;91:457-61.

15. Korovessis P, Papazisis Z, Koureas G, Lambiris E. Rigid, semirigid versus dynamic instrumentation for degenerative lumbar spinal stenosis: a correlative radiological and clinical analysis of short-term results. Spine. 2004;29:735-42.

16. Putzier M, Hoff E, Tohtz S, Gross C, Perka C, Strube P. Dynamic stabilization adjacent to single-level fusion: part II. In the clinical benefit is asymptomatic initially degenerated adjacent segments after 6 years follow-up. Eur Spine J. 2010;19:2181-9.

17. Chan D, Song Y, Sham P, Cheung KM. Genetics of disc degeneration. Eur Spine J. 2006;15(Suppl 3):S317-25.

18. Chalmers TC, Celano P, Sacks HS, Smith H Jr.Bias in treatment assignment in controlled clinical trials.N Engl J Med.1983;309:1358-61.

19. Moher D, Pham B, Jones A, Cook DJ, Jadad AR, Moher M, et al. Does quality of reports of randomized trials Affect Estimates of Intervention Efficacy Reported in meta-analysis? Lancet. 1998;325:609-13.
20. Schülke KF, Chalmers I, Hayes RJ, Altman DG. Empirical evidence of bias. JAMA.1995;273:408-12.

21. Scharer N., Dubois G, Braunsweiler R. Static and dynamic test of a dynamic biomechanical neutralization system for the spine. In: White AA, Panjabi MM, editors. Clinical biomechanics of the spine. 2nd ed. Philadelphia: JB Lippincott; 1990. p.19-24.

22. Stoll TM, Dubois G, Schwrzenbach O. The dynamic neutralization system for the spine: a multicenter study of a novel non-fusion system. Eur Spine J. 2002;11(Suppl 2):S170-S8

23. Bono CM, Kadaba M, Vaccaro AR. Posterior fixation pedicle-based dynamic stabilization devices for the Treatment of degenerative diseases of the lumbar spine. J Spinal Disord Tech. 2009;22:376-83.

24. Markwald TM, Wenger M. Dynamic stabilization of lumbar motion segments by use of Graf's ligaments: results with an average follow-up of 7.4 years in 39 highly selected, consecutive patients. Neurochem Acta (Wien). 2003;145:209-14.

25. Wild A, Jaeger M, Bushe C, Raab P, Krauspe R. Biomechanical analysis of Graf's dynamic spine stabilization system ex vivo. Biomed Tech. 2001;46:290-4. 